REVISTA ARA N7 . VOLUME 7 . PRIMAVERA+VERÃO 2019 • GRUPO MUSEU/PATRIMÔNIO FAU-USP

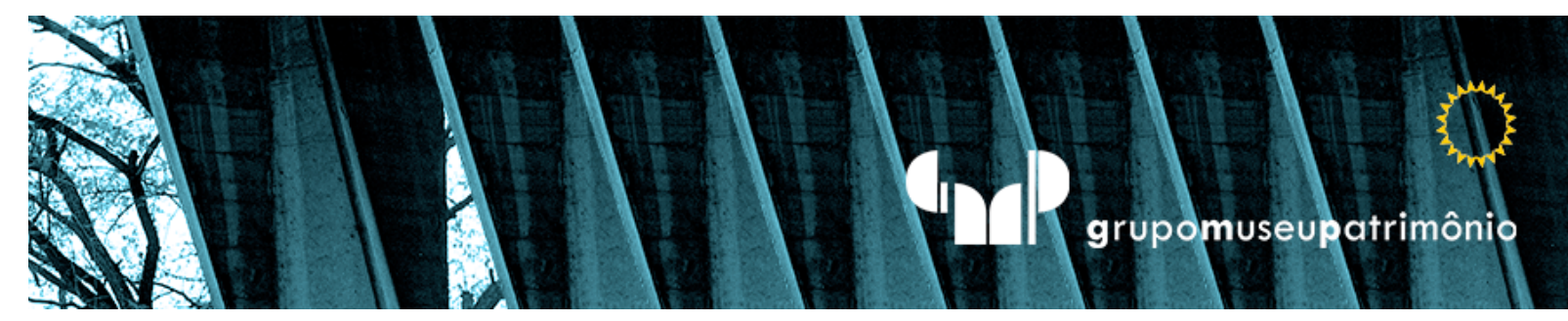

\title{
O Corpo Utópico e o programa performativo em ambiente urbano
}

\author{
El Cuerpo utópico y el programa \\ performativo en entorno urbano
}

The Utopian and the performative program in urban environment

\begin{abstract}
Luanna Jimenes $^{1}$
PGEHA-USP Programa de Pós-Graduação em Estética e História da Arte da Universidade de São Paulo. São Paulo-SP, Brasil. luannajimenes@usp.br

${ }^{1}$ Orientador: Arthur Hunold Lara
\end{abstract}




\section{Resumo}

Com o presente artigo pretende-se aproximar as noções de corpo utópico e heterotopia, desenhadas Michel Foucault, das práticas performáticas em contexto urbano. O imaginário que acompanha o corpo utópico será revisado considerando a circulação de imagens na cultura contemporânea, assim como o sentido de heterotopia do referido autor, permite refletir a experiência da fruição na cidade

Palavras-chave: performance, deriva, corpo, convívio, urbano.

\section{Resumen}

Este artículo tiene como objetivo reunir las nociones de cuerpo utópico y heterotopía, extraídas por Michel Foucault, de las prácticas performativas en un contexto urbano. El imaginario que acompaña al cuerpo utópico se revisará teniendo en cuenta la circulación de imágenes en la cultura contemporánea, así como el sentido de heterotópico del autor, permite reflejar la experiencia de fructificación en la cuidad.

Palabras clave: Performance, deriva, cuerpo, convivencia, urbano.

\section{Abstract}

This article aims to bring together the notions of utopian body and heterotopia, by Michel Foucault, from the performative practices in an urban context. The imaginary that accompanies the utopian body will be reviewed considering the circulation of images in contemporary culture, as the author's sense of heterotopy allows to reflect the experience of fruition on the city.

Keywords: performance, drift, body, conviviality, urban. 
No entanto, acredito que há - e em toda sociedade - utopias que têm um lugar preciso e real, um lugar que podemos situar no mapa; utopias que têm um tempo determinado, um tempo que podemos fixar e medir conforme o calendário de todos os dias.

Michel Foucault (2013, p.19)

\section{INTRODUÇÃO}

Em conferência radiofônica proferida em dezembro de 1966, M. Foucault declara que em todas as sociedades existem as utopias do corpo, os lugares demarcados e mesurados para vivermos um corpo incorpóreo, idealizado, muito próximo do perfeito ou mesmo que decrépito, um corpo que dificilmente coincide consigo mesmo. O corpo utópico aparece e desaparece, é habitante de um lugar "fora de todos os lugares" $(2013$, p.8).

Segundo os exemplos citados pelo autor, o corpo utópico surge do deslumbramento diante do fantástico, do país das fadas ou dos super heróis, onde é capaz de voar por entre os imensos edifícios; ou ainda o corpo abatido no cemitério, petrificado e eternizado sobre a lápide. As utopias narram, por meio de imagens, lugares que não existem para um corpo incorpóreo. Pelo 
discurso das imagens podemos reconhecer novas demarcações para o corpo, outros espaços e temporalidades.

Para refletir a experiência no cotidiano da cultura contemporânea e criar maneiras de reinscrever a escala humana na cidade, atualizar sua natureza corpórea em meio a estruturas agigantadas, faz-se necessário um conjunto de práticas.

Com o artigo pretende-se criar diálogos entre as noções de corpo utópico e heterotopia de M. Foucault e a arte da performance, do happening ${ }^{2}$, e dos programas performativos como derivas e deambulações. Verificar tais noções nos estudos de caso, descrever suas heterotopias, ou seja, notar de que maneira os programas performativos criaram "contra espaços, utopias situadas, esses lugares reais fora de todos os lugares" $(2013$, p.20). Ou ainda, os modos pelos quais a performance dispara situações inesperadas, inéditas noções de território no atual contexto das cidades vigiadas.

As performances citadas operam na chave do dispositivo de sociabilidade em que os artistas aderem "ao contexto material, social, político e histórico para a articulação de suas iniciativas performativas" (Fabião, 2011, p.5). Nota-se a ativação de relações de território e identidade, "mapeamento, de negociação e de reinvenção através do corpo- em experiência" (Fabião, 2013, p.5).

\section{EM DERIVA}

A estrutura material e simbólica das cidades constituem em sua totalidade ligações dinâmicas com experiências de comportamento. Para a arquiteta

\footnotetext{
${ }^{2}$ Happening foi o termo usado pelo americano Allan Kaprow em 1959 em Nova lorque para nomear as ações que aconteciam de maneira aparentemente espontânea, porém seguiam um roteiro previamente estabelecido. Kaprow pretendia incluir o publico no interior da obra de arte e perturbar a fruição passiva do observador. Com os happenings os artistas experimentavam desarticular a separação entre arte e vida. $O$ caráter crítico e provocador dos happenings em Nova lorque a partir de segunda metade da década de 1950, se deve à contradição da sociedade americana, o rápido crescimento econômico e aumento do consumo em simultâneo à Guerra do Vietnã (1955-1975).
} 
Paola Jacques Berenstein ${ }^{3}$, acontece na atualidade uma espécie de apatia ou empobrecimento da experiência na cidade:

“A redução da ação urbana, ou seja, o empobrecimento da experiência urbana pelo espetáculo leva a uma perda da corporeidade, os espaços urbanos se tornam simples cenários, sem corpo, espaços desencarnados. Os novos espaços públicos contemporâneos, cada vez mais privatizados ou não apropriados, nos levam a repensar as relações entre urbanismo e corpo, entre o corpo urbano e o corpo do cidadão." (2008).

A crítica articulada pelos situacionistas ${ }^{4}$ se mantém pertinente na atual cidade global. Ao permanecer por alguns períodos de tempo em uma praça de grande circulação de pessoas em São Paulo sem nada a fazer, apenas observar, notase que os passantes de modo geral parecem ausentes. Ou ainda, no interior do transporte coletivo, lugar configurado como "um amálgama extraordinário de relações porque é algo que atravessamos, é também algo que nos leva de um ponto a outro, e, por fim, é também algo que passa por nós" (Berenstein, 2003, p.53), podemos ver se instaurar em meio às multidões em circulação, uma espécie de passividade.

Deambular observando o entorno desencadeia imediatamente uma dissonância por oposição ao fluxo acelerado da cidade. Com as derivas "devemos construir ambiências novas que sejam ao mesmo tempo produto e instrumento de novos comportamentos" (Berenstein, 2003, p.53). O mineiro Paulo Nazareth ${ }^{5}$ tem feito caminhadas com dimensões continentais, testando no percurso programas e performances em diferentes países e contextos. Em uma região de circulação de pedestres em Nova Délhi em 2006, Paulo sentou-

\footnotetext{
${ }^{3}$ Paola Jacques Berenstein é docente na Faculdade de Arquitetura da UFBA.

${ }^{4}$ A experiência de deambular pelas vias urbanas retoma de maneira direta o movimento Internacional Situacionista em Paris na metade do século XX, assim como os procedimentos de resistência à cidade espetacular.

${ }^{5}$. O artista Paulo Nazareth (Minas Gerais 1977) cria instalações, objetos e registros audiovisuais de performances que acontecem no decorrer de suas longas caminhadas. Na exposição Notícias de América em 2011 na Art Basel de Miami estavam os registros e apropriações da travessia que começou em Governador Valadares em Minas Gerais e terminou em Miami, a pé de carona e canoa. Em 2013 foi convidado pela $12^{\mathrm{a}}$ Bienal de Lyon a expor os Cadernos de África, documentações no decorrer da travessia por toda a África de Johannesburg a Lyon.
} 
se sobre um tapetinho à beira de uma escadaria exibindo um papel com a seguinte mensagem: I pay one ruppe for someone guess where i am from. Nos registros em fotografia disponibilizados pelo artista, vemos Paulo cercado por dezenas de homens indianos visivelmente intrigados. (Figuras 1 e 2)

Por um rápido plano visto de cima pode-se prever a acelerada desordem provocada pelo gesto, tão preciso quanto simples, sugerindo complexas relações de alteridade e território. Apesar do tumulto ao seu redor, Paulo se mantém sentado, apenas respondendo negativamente às tentativas lançadas, numa atitude de gesto mínimo com grandes efeitos, "o gesto silencioso e medido, desencadeando por si só a transformação de sentido de uma situação" (Galard, 1997, p.51).

A ação One Ruppe For My Country se aproxima da noção de heterotopia quando o artista estabelece ao redor de si um espaço-temporal "absolutamente diferente" (Foucault, 2013, p.19) ${ }^{6}$, notadamente particular e sem comparativos. A ação chega no limite da ordem local quando o policiamento é acionado para evitar maior descontrole. O passante interrompido no seu cotidiano, foi convidado a atualizar seus conhecimentos olhando para o artista colocado como um problema da geopolítica global.

A atmosfera é de completa indefinição para os dois lados. Paulo Nazareth, sempre sentado de pernas cruzadas numa atitude de aparente receptividade não deixa de expressar uma contradição pelo risco que corre com a provocação. Podemos notar sua corporeidade no registro disponibilizado pelo artista, trata-se de uma "prática de criação de corpo que só pode acontecer no confronto direto com o mundo" (Fabião, 2011, p.10). Na duração do programa e local onde se instalou, entre o corpo do artista e dos passantes, instaurou-se diferentes noções de espaço e duração.

\footnotetext{
${ }^{6} \mathrm{O}$ grifo dado pelo autor se referindo a radical oposição entre os espaços heterotópicos e todos os outros, os espaços de passagem da cidade, circulação e o espaço privado da residência... Os espaços de heterotopia ressignificam todos esses lugares.
} 

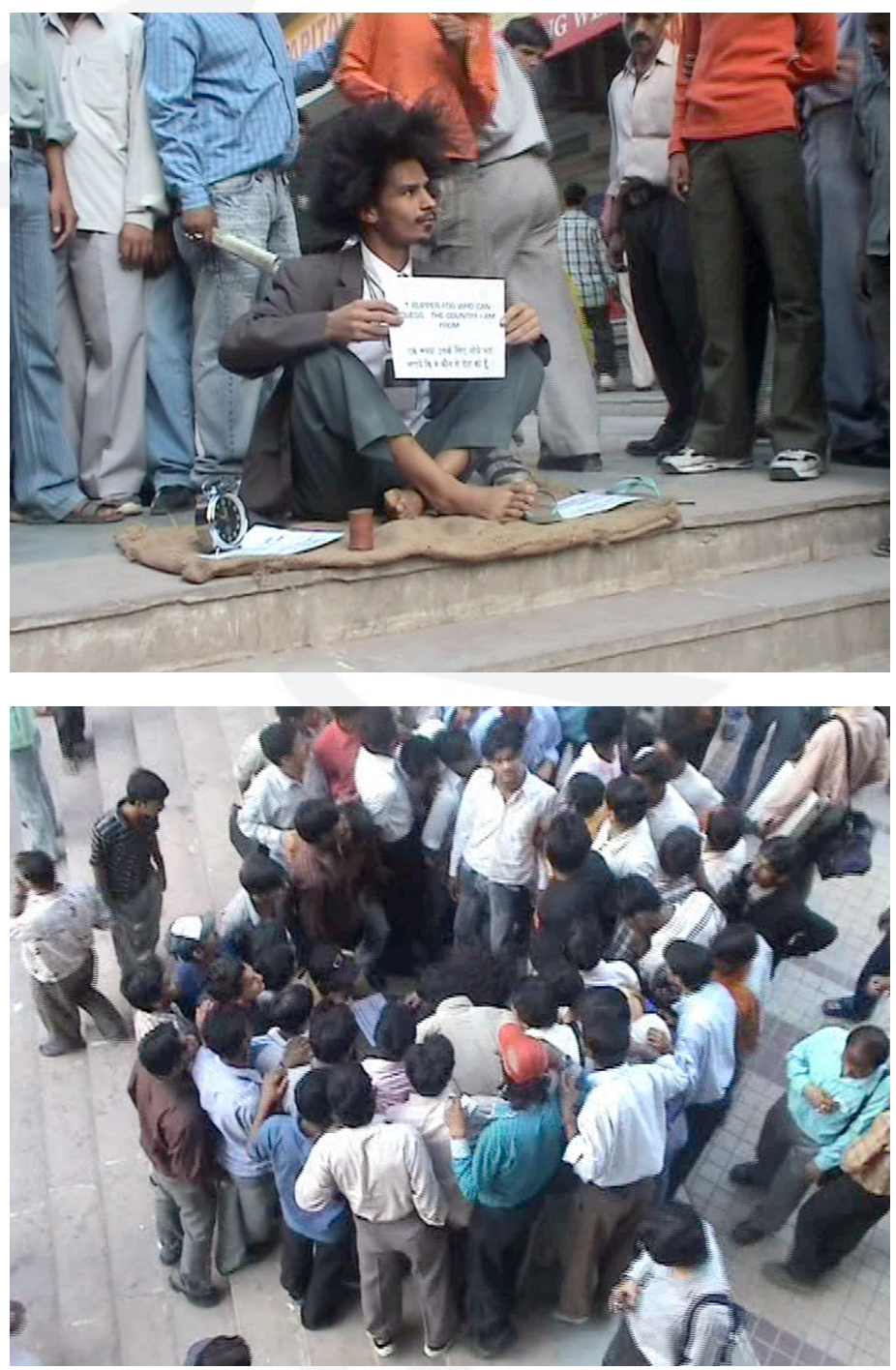

Figuras 1 e 2: One Rupper for My Country, 2006. Fonte: Cortesia Mendes Wood DM, São Paulo/Nova York/ Bruxelas

\section{UMA UTOPIA PARA O CORPO}

Foucault nos prepara para uma ciência que relaciona corpo e espaço. Nas utopias protagonizadas pelo corpo um discurso é narrado pelas imagens, somos deslocados para lugares e situações nas quais podemos existir inertes à 
finitude do corpo, "para suportar a condenação nascem as utopias" (2013, p. 8).

Diante do gigante ou do claudicante, dos super-heróis do cinema às narrativas religiosas; especialmente na atualidade, somos a todo tempo mediados pelas imagens: a exploração imagética para um corpo incorpóreo aparece na cultura contemporânea capturada pela tela total ${ }^{7}$.

Não faltam simulações para o incorpóreo em espaços espetaculares de exaustiva simulação. O corpo incorporal desenhado por Foucault, "veloz, colossal na sua potência, infinito na sua duração" $(2013$, p. 8) pode estar na atualidade reduzido à mera imagem.

Seguindo os exemplos citados pelo autor, do mais antigo mito ocidental da alma que nos dá existência imaterial e eterna; à tatuagem e a vestimenta, que "fazem do corpo um fragmento de espaço imaginário que se comunicará (...) com o universo do outro"(Foucault, 2013, p.12); se observarmos os passantes da via pública de uma cidade global como São Paulo, parece necessário procurar outros preceitos para reparar a questão da ausência e notável apatia.

Para Jean Baudrillard, as exaustivas imagens em circulação na tela total da rede digital são obscenas, no sentido de que nada escondem, são sedutoras e sem falhas, feitas de "signos permutáveis segundo a lógica da mercadoria" (Apud Fabbrini, 2016, p.245). Fascinados pelas imagens "edulcoradas" (ibidem, p. 245), somos antecipados por modelos que substituem a experiência da vida vivida.

Hoje a abstração já não é a do mapa, do duplo, do espelho ou do conceito. A simulação já não é a simulação de um território, de um ser referencial, de uma substância. É a geração pelos modelos de um real sem origem sem realidade: hiperreal. (1991, p. 8)

\footnotetext{
${ }^{7}$ Para Jean Baudrillard a tela-total é um jogo de palavras conjugando a ideia de dominação das telas de televisão, cinema, computador, etc.
} 
O imaginário protagonizado pelo corpo ou a utopia de um corpo que "seria belo, límpido, transparente, luminoso, (...) sempre transfigurado" (Foucault, 1994, p.8), é capturado pela exaustiva interação com as imagens amplamente difundidas pela tela total. Somos fascinados por imagens que substituem a experiência.

Diante dos dispositivos virtuais com os quais convivemos no séc. $\mathrm{XXI}$, vemos comprimir a experiência da duração e das distâncias. Este fenômeno foi precedido pela inércia diante de sucessivas paisagens emolduradas pela janela do automóvel nas autoestradas para alta velocidade. Perdemos a conexão com o território e sua extensão desde que cruzamos grandes distâncias confortavelmente acomodados no interior do automóvel ou do avião.

\section{TECENDO HETEROTOPIAS}

No atual contexto, em que os sentidos do corpo estão capturados por imagens hiper-reais em espaço-tempo comprimido, vale mobilizar a noção de heterotopia transmitida por Foucault. Para ele, sem dúvida não há sociedades sem heterotopia, é "uma constante em todo o grupo humano" (Foucault, 2013, p.8). Podemos até "classificar as sociedades, por exemplo, segundo as heterotopias que elas preferem, segundo as heterotopias que elas constituem"(Foucault, 2013, p.21). Os exemplos citados pelo autor para refletir os espaços de heterotopia: o jardim, a colônia de férias, os colégios de rapazes, o cemitério, o teatro... nos incita a refletir os lugares de heterotopia no atual contexto urbano da cidade global.

A artista e pesquisadora carioca Eleonora Fabião ${ }^{8}$ experimentou em diferentes capitais pelo mundo suas Ações. Um catálogo com a documentação da experiência foi publicado com apoio do prêmio Rumos Itaú Cultural em 2015, com imagens, anotações e textos críticos. Eleonora através de sua prática

\footnotetext{
${ }^{8}$ Eleonora é docente ligada ao programa de formação em Artes da Cena na UFRJ.
} 
performática "desprograma a si e ao meio (...) acelera circulações, intensidades, deflagra encontros, reconfigurações, conversas, faz coisas acontecerem" (2013, p. 5).

Nas Ações, com poucos materiais mas enunciados bem formulados, Eleonora informa um processo estético-político, inserindo objetos do cotidiano em tarefas aparentemente sem sentido.

Em Ação carioca \#7: Jarros, Eleonora permanece em frente à estação carioca do metrô transferindo de um jarro a outro, um de barro e outro de prata, uma porção de água até evaporar. "Foram necessárias mais de quatro horas para fazer $300 \mathrm{ml}$ de água desaparecer" (2015, p. 41). Em seu diário ela descreve a interação com uma passante que a aborda para entender do que se trata. A ação se repetiu em Fortaleza, intitulada Ação Fortalezense \#5. Eleonora descreve em seu diário a diferença cultural e dos temperamentos no convívio público nas diferentes capitais, os sentidos e associações levantados pela mesma ação nos dois contextos.

No Rio de Janeiro, a artista na porta da estação do metrô ocupada com a tarefa que, para uma passante não tinha sentido, em Fortaleza o gesto tinha todo o significado e merecia ser acompanhado. Em Fortaleza um grupo de pessoas se propõem a ajudá-la numa espécie de trabalho coletivo rapidamente assimilado.

\footnotetext{
"Eleonora, por via da sua performance - que invocam e ativam tempos descolados de circuitos cronométricos, tempos quase matéria de tão vibráteis e que a arrastam para um estado outro, um pouco para lá da sincronia. Lá, num tempo- limite e num estado de existência fora dos eixos, ela age e faz agir." (Lepecki, 2015, p.332).
}

A experiência da duração na tarefa com as jarras pode estar próximo do que Foucault chamou tempos ucrônicos. Em contraste com a cidade acelerada em contínua produtividade mercantil, um trabalho de aparente inutilidade se instala com duração a verificar, provoca ao redor o imprevisto.

Desde a deriva situacionista a duração, em oposição à crescente aceleração da cidade, é uma estratégia para novas maneira de habitar. Mover-se mais 
lentamente não significa definir uma duração objetiva como sendo devagar, mas relativa e subjetiva, "significa uma outra forma de apreensão e percepção do espaço urbano, que vai além da representação meramente visual" (Jacques, 2008); algo em oposição ao corpo passivo pelo excesso de velocidade.

Para Renato Cohen, a performance é uma arte de fronteira "no seu contínuo movimento de ruptura [...] tocando nos limites entre vida e arte." (2013, p. 38). Segundo ele, a performance está ligada a um movimento maior, a Live Art, a arte ao vivo e também a arte viva, que consiste em "uma maneira de encarar a arte" (2013, p.38), em resgate de seu caráter ritual e capacidade modificadora do instante presente pela ritualização de atos comuns da vida cotidiana como dormir, comer e andar.

Ao notar no cotidiano a adesão do corpo a aspectos imateriais, vale se aproximar da dança por uma nova acepção de coreografia. "A dança entendida como teoria social da ação, e como teoria social em ação" (Lepecki, 2012, p.45). Segundo Lepecki, a coreografia é essencialmente não metafórica e puramente materialista, não deve ser entendida como imagem, alegoria, ou metáfora política, mas como a disposição que manipula os corpos uns em relação aos outros.

Essa necessária antimetaforicidade requer a formação de um empirismo particular, atento aos modos como coreografias são postas em prática, ou seja, dançadas. Antimetaforicidade requer entendermos de que modo, ao atualizar-se, ao entrar no concreto do mundo e das relações humanas, a coreografia aciona uma pluralidade de domínios virtuais diversos - sociais, políticos, econômicos, linguísticos, somáticos, raciais, estéticos, de gênero - e os entrelaça a todos no seu muito particular plano de composição, sempre à beira do sumiço e sempre criando um por-vir. (2012, p. 46)

Ao contrário da ideia de que os habitantes da cidade podem se mover livremente, o que se percebe são rígidos limites para o corpo restrito ao mínimo. Nas ruas de São Paulo vemos o corpo dos habitantes controlado por uma coreografia desenhada por preceitos materiais e imateriais externos a ele, 
uma espécie de "suporte necessário para conter a efemeridade, a precariedade, o deslimite do agir" (Lepecki, 2012, p. 48).

Foucault, poucos anos depois da transmissão radiofônica intitulada heterotopias, foi convidado pelo grupo de arquitetos do círculo de estudos arquiteturais de Paris para uma conferência. Nesse contexto o pensador atualizou sua noção de heterotopia para heterotopologia; estava em curso sua genealogia dos equipamentos coletivos, uma pesquisa empírica em equipamentos hospitalares que, segundo ele, se tornaram acima de tudo estruturas de vigilância.

O que está em relação ao corpo e o informa, controla e vigia, se reproduziu em outras formas arquiteturais, nos mais variados equipamentos que compõem a cidade. Porém para Foucault, não se trata de analisar formas arquiteturais mas tecnologias do poder.

Diante desta realidade o gesto do artista com seus programas de ação, reconfigurando por um momento o ambiente e as relações, na escala de seu corpo, abre questionamentos diante de estruturas agigantadas. Ainda que seja evidente a incompatibilidade de escala, o dissenso, uma experiência, fica impressa nos corpos do que ali estiveram

A experiência de duração na performance Permanência para os Encarnados, de autoria da pesquisadora que aqui escreve, permite refletir as noções de corpo utópico e heterotopia. A performance consiste na permanência por no mínimo 5 horas caracterizada por um traje que cobre todo o corpo. A ação teve oito horas de duração numa sexta-feira em julho de 2015 no Largo da Batata em Pinheiro, São Paulo, região de grande circulação de pessoas em torno da estação Faria Lima do metrô.

A corporeidade que sustenta a permanência é a expansão da respiração com dimensões e tempos orgânicos, sendo portanto um expandir e recolher até limites extremos, alternando uma figura grande a outra pequena próxima do chão. As pausas no percurso permitiam múltiplas leituras. A indumentária de 
tecido preto encorpado e com algum brilho, por alguns momentos faz desaparecer a figura humana em detrimento de um constructo.

O programa atua como um dispositivo de presença e encontro e provocou contaminações nos passantes (figura 3). Pela duração insistente em silêncio, a performance Permanência para os Encarnados produz incômodos quando distorce a noção de tempo e corpo cotidianos. A ação vem despertando efeitos curiosamente diferentes em relação ao entorno, porém é unânime questionamentos acerca da não identificação de gênero.

Cobrir-se e recusar ser identificado em convívio público produz inúmeros desconfortos; alguns se arriscaram em investigar a figura, se aproximando para ver por entre as fendas do traje. Diante da constatação de se tratar de uma mulher, foram recorrentes os ataques testando os limites. Quando protegida por agentes de mediação, inserida em programações e eventos culturais, notou-se fruição mais interrogativa, mas ainda assim houveram aglomerações de um público masculino à espera do término.

A performance aconteceu em diferentes cidades, foi possível pôr a prova o comportamento dos transeuntes e habitantes de diferentes procedências. Diante da indefinição de um sujeito e um propósito, a atmosfera ao redor é sempre de dúvida, o que provocou inevitáveis diálogos entre pessoas desconhecidas. (Figuras 4 e 5).

A permanência por oito horas sem intervalo, sem ver o entorno mas ouvindo, tornava-me profundamente sensível ao ambiente, à luz do sol... Foi como entrar em contato com tudo, com o imediatamente ao redor, os passantes, as edificações, os automóveis em movimento, os aviões; mas também com uma duração eterna e desmedidas porções de território.

Quanto ao corpo, não existiram discursos imagéticos para um corpo forte e resistente que me ajudasse a continuar, sua condição material se tornou líquida fluidez. A imagem de um corpo inabalável foi substituída pela experiência corpórea sem imagem, mas pura sensação. No que se refere ao 
espaço, na medida em que a ação durava, o ambiente deixou de ser uma localização no mapa da cidade, mas se tornava uma porção da topografia.

Afinal, a ciência preparada por Michel Foucault na década de 1960 merece contínuas atualizações. Em diálogo com a prática da performance, as noções de corpo utópico e heterotopia nos permite refletir o problema da cultura contemporânea: quando o corpo é invariavelmente reduzido a mera imagem, e por ela somos mediados; e a experiência do espaço-tempo comprimidos.

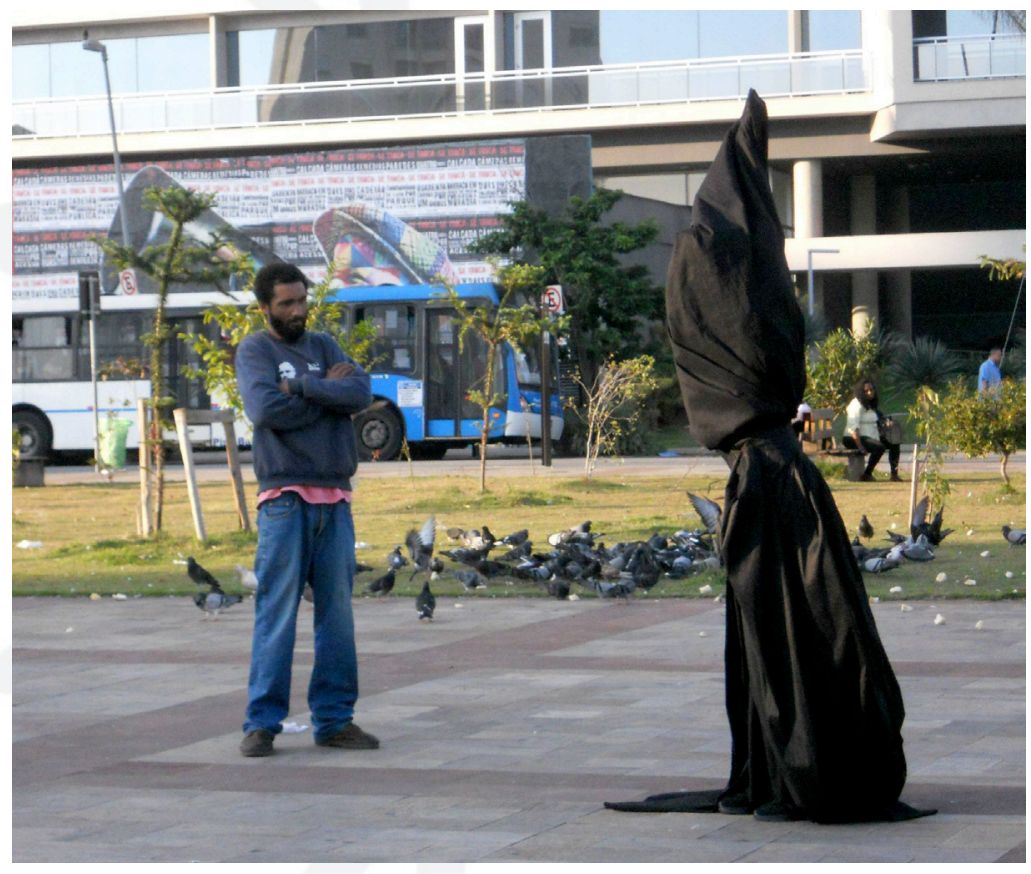

Figuras 3: Permanência para os Encarnados, 2015. Fonte: Érico Marmiroli 

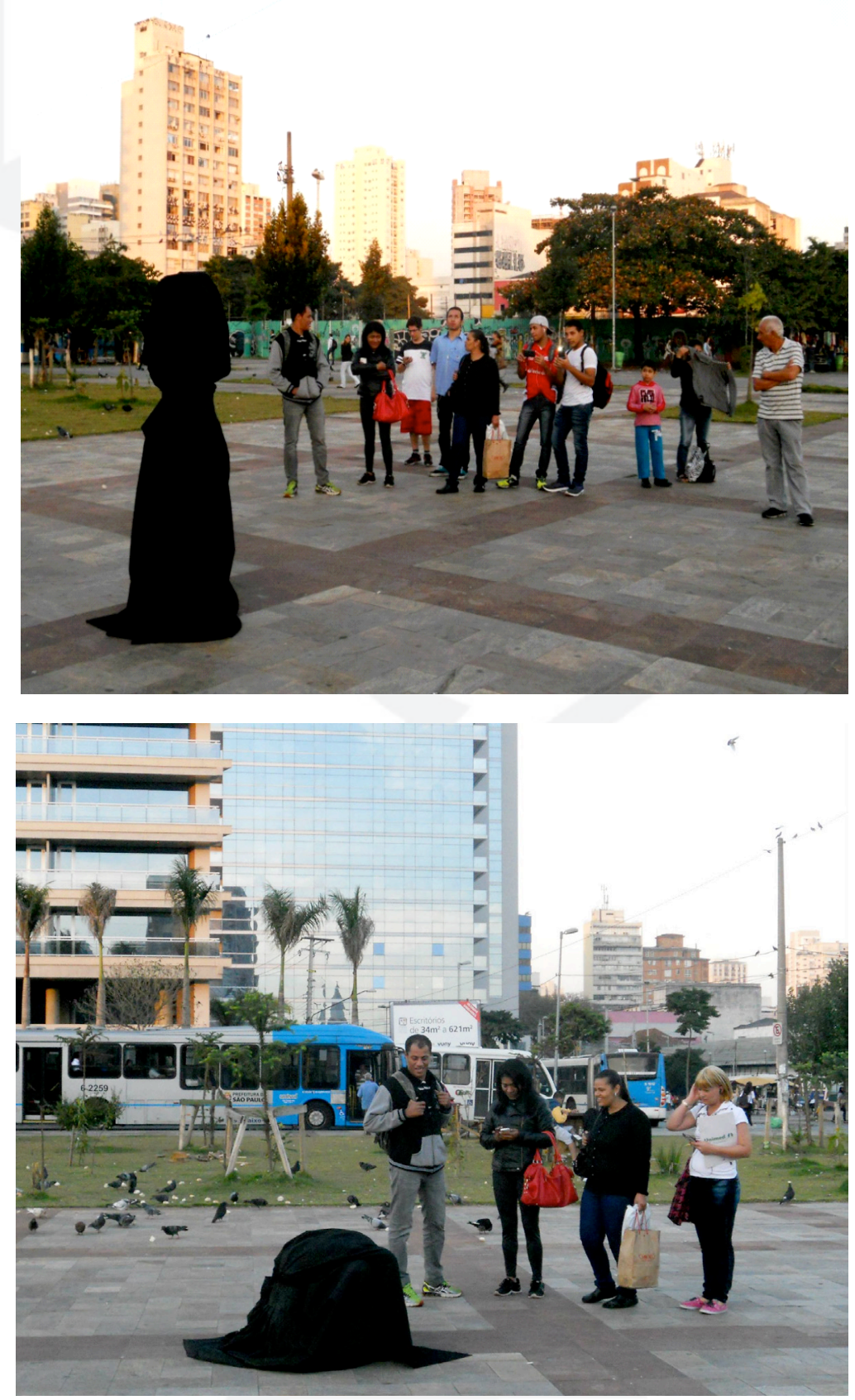

Figuras 4 e 5: Permanência para os Encarnados, 2015. Fonte: Érico Marmiroli 


\section{BIBLIOGRAFIA CITADA}

Baudrillard, Jean. Tela Total: mito-ironias da era do virtual e da imagem; tradução de Juremir Machado da Silva. 4. Ed. Porto Alegre: Sulina; 2005. . Simulacros e Simulação. Trad. Maria João da Costa Pereira. Lisboa: Relógio d'água; 1981.

Bragança de Miranda. José A. O Corpo utópico. Cadernos Pagu (15) 2000: pp.249-270. Professor do Departamento de Ciências da Comunicação, Faculdade de Ciências Sociais e Humanas da Universidade Nova de Lisboa; responsável pela Área de Comunicação e Cultura; presidente do Centro de Estudos de Comunicação e Linguagens (www.cecl.pt).

Cohen, Renato. Performance como Linguagem. São Paulo: Perspectiva; 2013.

Fabião, Eleonora. Ações. Rio de Janeiro: Tamanduá Arte; 2015.

Programa performativo: O corpo-em-experiência. Revista do Lume, n 4, dez 2013.

"Performance: modos de pertencer e criar mundo" In: Bienal Internacional de Dança do Ceará. Um Percurso de Intensidades (Fortaleza: Expressão Gráfica e Editora, 2011)

Jacques, Paola. B. (org.) Apologia da Deriva: Escritos situacionistas sobre a cidade. Rio de Janeiro: Casa da palavra; 2003.

Corpografias Urbanas. Portal Vitruvius, sessão

Arquitextos, 2008.

http://www.vitruvius.com.br/arquitextos/arq093/arq093_02.asp (último acesso em outubro de 2018.

Galard, Jean. A beleza do gesto: Uma estética das condutas. São Paulo: Edusp; 1997

Fabbrini, Ricardo. Imagem e enigma. In: Viso: Cadernos de estética aplicada, v. X, n. 19 (jul-dez/2016)

Foucault, Michel. O corpo utópico, as heterotopias. São Paulo: n-1 edições, 2013

. De outros espaços. Conferência proferida por Michel Foucault no Cercle d'Études Architecturales, em 14 de Março de 1967. Tradução a partir do inglês (com base no texto publicado em Diacritics; 
16-1, 1986) de Pedro Moura.

https://escolanomade.org/2016/02/23/615/ Último acesso 10/7/2019

Lepecki, André. Coreopolítica e coreopolícia. ILHA v. 13, n. 1, p. 41-60, jan./jun. (2011) 2012 